\title{
Equity factors during the COVID-19 pandemic: Difficulties in emergency remote teaching (ert) through online learning
}

\author{
Orit Ezra $^{1} \cdot$ Anat Cohen $^{1}$ (D) $\cdot$ Alla Bronshtein ${ }^{2} \cdot$ Hagit Gabbay $^{1} \cdot$ Orit Baruth $^{1}$
}

Received: 13 January 2021 / Accepted: 8 June 2021 / Published online: 29 June 2021

(c) The Author(s), under exclusive licence to Springer Science+Business Media, LLC, part of Springer Nature 2021

\begin{abstract}
Since the onset of the COVID-19 pandemic, Emergency Remote Teaching through Online Learning (ERT-OL) has become the prevalent form of learning at many universities worldwide. At the same time, voices around the world have pointed to difficulties in online learning in general and to concerns regarding educational equity in particular. The current study sought to increase knowledge about specific hindering elements in ERT-OL and about the relationships between these elements from the standpoint of the following equity factors-socioeconomic status, language, and juggling among students who are also parents or working. To this end, the study analyzed 154 open-ended textual statements concerning the difficulties perceived by students at a university in Israel. The qualitative thematic analysis generated a map of hindering elements categorized in terms of a) processes: technology, pedagogy, content, situation and individual characteristics, and b) outcomes: cognitive, affective, social, and physical. The map revealed a mesh of intricate mediating and moderating links whose effect can intensify for each equity factor. On the positive side, seeds of mitigating strategies emerged as well. The study advances knowledge regarding ERT-OL hindering elements and their relationships and provides a better understanding of how these debilitating relationships may be exacerbated when equity factors are considered. Researchers and teachers interested in ERT-OL or in "normal" online learning in the future can use the map as a research and teaching framework to identify inequities and prevent further gaps.
\end{abstract}

Keywords Equity $\cdot$ Coronavirus (COVID-19) $\cdot$ Distance learning $\cdot$ Emergency remote teaching $\cdot$ Online learning difficulties

Anat Cohen

anatco@tauex.tau.ac.il

Extended author information available on the last page of the article 


\section{Introduction}

In dealing with the COVID-19 pandemic, many universities worldwide have shifted to distance online learning (Altbach \& De Wit, 2020). This unplanned and hasty shift to a new form of teaching is known as Emergency Remote Teaching (ERT) (Hodges et al., 2020). In this study we further refine this concept to ERT through Online Learning (ERT$O L$ ). Yet even before the COVID-19 outbreak, the literature already pointed to substantial difficulties accompanying online learning (Islam et al., 2015), with some scholars also noting potential causal relationships between these difficulties (Gillett-Swan, 2017). Therefore, the various reports of ERT-OL difficulties during the COVID-19 pandemic circulating for some time now (e.g., Bao, 2020) should come as no surprise.

As ERT-OL expands, another reverberating theme refers to diminished educational equity in schools (Reich et al., 2020) and higher education institutions (Maloney \& Kim, 2020). Equity factors discussed before and during the pandemic crisis include but are not limited to lower socioeconomic status (SES) (e.g., Girik Allo, 2020); a first language that differs from the language of instruction (e.g., Reich et al., 2020); and juggling among parenting students and/or working students (e.g., Abbott-Chapman et al., 2004; Santhanam, 2020). Thus, both past and current reports about COVIDrelated ERT-OL point to greater difficulties among special populations.

Considering the need to enhance knowledge about ERT-OL hindering elements in higher education during the COVID-19 pandemic, and given the paucity of information about the specific relations between these hindering elements in general, and in conjunction with equity factors in particular, this study sought to listen to students' perceived difficulties in this new and unprecedented situation. The study aimed to analyze the ERT-OL hindering elements, map the relations between these hindering elements, and understand the potential impact of ERTOL hindering elements from an equity standpoint. Such enhanced knowledge may help identify and prevent further inequities and gaps among special populations.

\section{Literature}

\subsection{ERT-OL difficulties during the COVID-19 pandemic}

The lockdown imposed due to the spread of the coronavirus led campuses worldwide to shut down and then shift to distance learning to prevent cancellation of the semester (Altbach \& De Wit, 2020). The change from a face-to-face format to ERT through online learning (henceforth termed ERT-OL) was swift. Hence, it lacked the meticulous planning and design essential for high-quality online learning during "normal" times (Hodges et al., 2020). Online learning, alternatively called e-learning (Moore et al., 2011), refers to the use of computer technology tools to enhance learning and teaching, often through the use of internet technologies that deliver information and improve knowledge and performance (Keengwe et al., 2012). The unprecedented magnitude of this educational transformation 
(Yan, 2020)—which was facilitated by the use of technological resources and tools that offer functions such as synchronous or asynchronous access, communication and course management (Aparicio et al., 2016)— has enabled students to continue their study routine from home, despite the challenges. The many benefits of online learning, such as flexible learning time and place, have been documented both before and during the COVID-19 crisis (Hodges et al., 2020; Lall \& Singh, 2020).

Online learning, however, is not without its difficulties. A literature review by Islam et al. (2015) discussed broad categories of e-learning challenges, including pedagogical difficulties in group interaction, technological constraints in quality of e-learning systems and their adaptability to academic requirements, and concerns regarding diverse student learning styles. Gillett-Swan (2017) noted barriers faced by isolated online learners: inhibited group work related to an inability to draw upon non-verbal cues and body language; challenges involving the creation of a sense of community among online learners; teachers' inability to see students, causing them to overlook students' needs; limitations of specific software that slow down interaction, add to time limitations, increase frustration and hamper sense of community; and insufficient technical competency among students and teachers, making simple tasks complex.

Given the disruptive, swift, and unplanned shift to providing all courses online (Bao, 2020) and considering the prior literature summarized above, it is no surprise that recent studies have highlighted difficulties in ERT-OL experienced across the globe during COVID-19. A recent study in Israel coded and categorized Israeli students' perceived difficulties into non-helpful dimensions. The prevalent concerns include concentration (student dimension), teaching quality (teacher dimension), technical issues (learning environment dimension), and attention to student difficulties and course requirements (institution dimension) (Ezra et al., 2021). A study from India by Lall and Singh (2020) classified the most commonly perceived problems in terms of co-curricular activities, meeting friends, language, two-way communication and network connectivity. Bao (2020) discussed problems that surfaced in Chinese social media in response to the new mode of learning. These problems do not come from technical obstacles and mainly concern students' self-discipline and home learning environment.

Hence, it is imperative to explore the elements that hinder ERT-OL during the COVID-19 pandemic, including the relations between these elements. To this end, more knowledge is required in this area, especially since the literature contains very few detailed investigations of specific relationships among the elements hindering online learning.

\subsection{Educational equity within ERT-OL during the COVID-19 pandemic}

Numerous studies and reports from around the world on ERT-OL during the COVID-19 pandemic have highlighted the decrease in educational equity caused by the shift. Educational equity means that all students have access to the educational resources they need, such that personal and social identifiers are not obstacles to accessing educational opportunities (The Aspen Education \& Society Program \& the Council of Chief State School Officers, 2017). A report surveying the response of the US K-12 system to the pandemic focused on equity issues and called upon 
state agencies to provide schools with more guidance in handling special populations experiencing shortages in various factors (Reich et al., 2020).

\subsubsection{Equity factors: SES}

Some studies investigating educational equity emphasize the SES factor. Low SES is characterized by low income, in turn triggering digital inequity (aka digital divide) reflected in disparities in technology access (Collin \& Brotcorne, 2019). Recent COVID-19 ERT-OL studies have also reported a prevalence of inadequate essential technological resources such as internet connection and equipment among college students from low-income backgrounds. Most respondents in study in the Philippines do not have adequate hardware and software or internet access. The study shows that lower income is an obstacle to e-learning readiness, including access to proper equipment and sufficient internet connection (Alipio, 2020). In Bangladesh, internet service is expensive, scarce internet facilities in rural areas force students to rely on poor mobile internet signals, and many students still use their mobile phones for study purposes (Alam, 2020). In Indonesia, some students have limited financial resources which limit their data quota, a problem that has intensified in remote areas with limited service. Group work is thus necessary to compensate for those with more limited access to information. Hence, students prefer low-bandwidth consumption apps such as Messenger rather than bandwidth-consuming e-learning systems (Girik Allo, 2020).

\subsubsection{Equity factors: Language}

The language equity factor is a consequence of having a first language different from the language of instruction. According to socially situated learning theories, language has a dual function in learning in that it facilitates communication for sharing and developing knowledge, and organizes individual thoughts for reasoning, planning, and reviewing actions (Conole et al., 2004). Additionally, speaking enables learners to participate in a community of practice, providing further access to learning (Lave \& Wenger, 1991). Indeed, research has shown that mother tongue instruction is crucial to effective learning, including in bilingual education for immigrants or for indigenous people integrated into mainstream society (Bühmann \& Trudell, 2008).

The literature on English Language Learners (ELLs) in English-dominant classrooms has confirmed that English as a mediational tool is a limiting factor in academic development (Iddings, 2005). A study in Israel found that immigrants with a strong previous native language mathematics instruction still lag behind native speakers even after a long period of residence, presumably due to insufficient proficiency in the language of teaching (Levin \& Shohamy, 2008). The implications of non-native language instruction resonate throughout the online world. In the context of online learning programs taught in English at a large university in South Australia, Hannon and D'Netto (2007) showed that the perceived ability to work with online learning technology is higher among native English-speaking Australian students. The aforementioned report on the response to the pandemic in the US K-12 system illuminated the urgency to adapt to the new ERT-OL situation and accommodate the special needs of ELLs (Reich et al., 2020). 


\subsubsection{Equity factors: Juggling}

The juggling factor refers to difficulties faced by working students and parenting students who must juggle multiple life demands such as job and family responsibilities along with their academic workload (Tsay et al., 2018). Juggling home, work and study serves as an obstacle for these students, while university and family support is helpful to them (Abbott-Chapman et al., 2004). Over the years, part-time work has increased among full-time students because they need the money and the work experience, with deleterious consequences for study time and dropout rates (Hall, 2010; Hovdhaugen, 2013). Attending regularly scheduled classes is a challenge for jugglers, even in online distance learning that offers more flexibility (Brooks, 2012; Gillett-Swan, 2017). The latest reports on working parents who must juggle jobs and child care during COVID-19 (e.g., Santhanam, 2020) and on workers who have no experience working from home or are reluctant to do so (Kramer \& Kramer, 2020) clearly point to intensified burdens faced by those who are also students.

In light of the need to enhance knowledge about the elements hindering ERT-OL during the COVID-19 pandemic and given the paucity of information about specific relations between these hindering elements in general, and in conjunction with equity factors in particular, this study sought to listen to the perceived difficulties of higher education student in this new, unprecedented situation. The study's specific objectives were: 1) to analyze the elements that hinder ERT-OL in higher education during COVID-19;2) to map the relations between these hindering elements; 3 ) to understand the potential impact of ERT-OL hindering elements in higher education from an equity standpoint. To meet these objectives, the study zoomed in on the following research questions: Q1) How do elements that hinder ERT-OL in higher education during COVID-19 impact students? Q2) What impact can these hindering elements have on educational equity with respect to language, SES and juggling?

\section{Methodology}

The study was conducted at one of Israel's largest universities among students studying in the School of Education. The study sought to "listen" to the students' experiences over the first few weeks of the shift to ERT-OL in order to focus on the transition point while minimizing memory bias. It also enabled sharing information with policymakers at early stages. It explored the students' perceived difficulties with ERT-OL as reported through an open-ended question delivered online. The qualitative methodology was suitable for early exploration of the new ERT-OL phenomenon.

\subsection{Participants}

One hundred fifty-four students enrolled in the School of Education (BA, MA, and $\mathrm{PhD}$ ) responded. The students take mandatory and elective courses in four areas of study: educational policy, science education and technology, counselling and special education, and multilingual education. The native language of most students is 
Fig. 1 Online learning hours per week

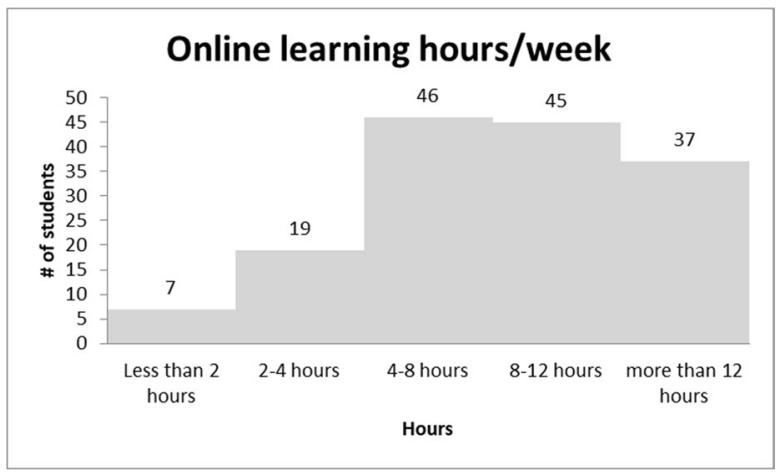

Hebrew, which is also the language of instruction in the courses, while some of the students speak other languages, e.g., Arabic and Russian, as their native language. Since we wanted the students to express their views openly and in as much detail as possible, we avoided collecting identifying details such as age and degree. We did, however, examine their weekly exposure to online learning and found that the majority spent more than four hours a week learning online and more than half (82) spent more than eight hours per week learning online (Fig. 1). Note that the distribution of learning hours reflects the nature of the school, where the majority are MA students who study one day a week.

\subsection{Research tools}

The online Hebrew questionnaire was distributed to the students at the end of March 2020, a few weeks after the shift to ERT-OL. The open-ended question prompted the students to elaborate on any difficulties they came across after switching to ERTOL. The participants answered in Hebrew. The excerpts in the paper were translated into English.

\subsection{Data analysis}

The thematic analysis method was used since this method facilitates identifying, analyzing and reporting patterns (themes) within data (Braun \& Clarke, 2006). First, we reviewed the 154 data items (students' answers to open question). Next, we coded the 154 data items (hindering codes) based on explicit semantic indications of difficulties in the content. The codes referred to the most basic segment of a perceived difficulty in the data item (items could match several hindering codes). Thus, 200 hindering codes were generated.

Next, we began developing the themes. First, categories can be used to classify findings to provide details for analytical theme development (Vaismoradi et al., 2016). Thus, to answer the first research question regarding the ERT-OL hindering elements, we developed categories aligned with existing theoretical concepts that aggregate hindering codes based on similarities (Maxwell \& Miller, 2008) and constructed the Q1 themes accordingly. To answer the second research question about the ERT-OL hindering 
elements from an equity standpoint, we decided to use the prevailing hindering codes that according to the literature were also relevant to language, SES and juggling factors (relevant codes). In each of these thematic analyses, we mainly examined prevailing relationships between these relevant codes and other codes in terms of co-occurrence and sequencing (Joffe, 2012). We established relations among and between the categories, enabling us to construct the Q2 themes. Therefore, the thematic analyses in this study are both inductive and deductive theory-driven analyses (Braun \& Clarke, 2012). Finally, we produced the report and selected compelling excerpts as examples. One researcher conducted the above process recursively, so that the codes, their categories and their relationships were continuously updated. The research team held discussions about the codes, categories, relationships, themes, and selected excerpts. The fact that the data were coded mainly by one researcher who was rigorously immersed in the data is in line with the adopted version of qualitative thematic analysis (Braun \& Clarke, 2006), wherein coding is treated as a flexible process requiring detailed engagement with the data. The assumption is that the coding develops depth beyond the obvious surface level through immersion in the data. This means the outcomes of the process can be stronger or weaker, but they cannot be right or wrong in any objective sense (Terry et al., 2017).

\section{Findings $\&$ discussion}

Here we present and discuss the findings for the two research questions. For the first question, we describe the categories and some sample hindering codes along with selected excerpts that illustrate the themes describing the ERT-OL hindering elements. For the second question, we delve into the relationships among and between the categories by zooming in on the relationships between the equity-relevant codes and other codes. We provide selected excerpts for each relationship and show the themes delineating the impact of ERT-OL hindering elements on equity through language, SES and juggling factors.

\subsection{COVID-19-ERT-OL hindering elements: TPACK process and cognitive-affective- social-physical outcomes}

Our analysis yielded an ERT-OL map consisting of three themes: 1) a theme comprising ERT characteristics, as well as integral 2) process and 3) outcome themes emerging from the underlying categories. All themes are based on the 200 hindering codes that emerged, as explained subsequently. In this section, we first explain the theme of ERT characteristics. We then clarify the process theme made up of the TPACK categories (Koehler \& Mishra, 2009; Rosenberg \& Koehler, 2015). Finally, we discuss the outcomes theme that is composed of cognitive-affective-social-physical outcome categories. The relations among these themes and their respective categories and codes are further discussed in the context of Q2.

The ERT characteristics theme refers to setting characteristics invariant for all ERT-OL learners during COVID-19. Study from home is a typical code in this 
theme in that, given the restrictions, all students studied at home: "Of course there is the issue of concentration, when we are at home, there are more distractions and there are always diversions." The process and outcomes themes cover the hindering codes representing differences between learners, who experience different hindering processes and thus encounter different outcomes. In the above example, unlike the constant factor of studying from home, diversions may vary between learners, as some may face home distractions while others do not. Hence, diversions are assigned to the process theme. Learners' consequent concentration may also vary

1. Learner individual characteristics

- Student disabilities

- "Due to the circumstances, the teachers give us large assignments (either as a task or as a

replacement for the lesson, self-learning). I have learning disabilities so this entails greater effort, more than I invest in a regular semester"

2. Teacher individual characteristics

- Teacher technical proficiency

- "It seems that not all the teachers have mastered the software, and sometimes they spend a great deal of time coping when they run into difficulties with basic operations"

3. Situation

- Different delivery methods and platforms

- "Mainly a mess, each course is delivered differently, using different software. Makes it really difficult to follow"

- Mail correspondence

- "We receive a lot of emails, some are university updates and some from teachers...the large number [of emails] makes us lose track"

- Schedule maintenance

- "It's hard when the class isn't live and we are referred to previous years, for me this disrupts the learning order"

4. Pedagogy

- Group work

- "It's difficult to do group work and I think that under the circumstances we should be allowed to submit individual work"

- Social learning

- "I can't study with my classmates, which is helpful for learning, at least for me"

5. Technology

- Technical issues

- "The teachers should be available for comments and questions before class starts in case the students can't connect to the room or come across a technical problem"

6. Content

\section{- Practicum/Workshops}

- "Some courses such as practicum are very difficult to deliver online. Courses that are usually in a workshop format with only a few participants "

- Mathematics

- "It's hard learning this way, especially mathematics subjects"

- Seminar - study execution

- "I am taking two seminars now. I am stuck at the filming stage. I have no way of filming groups due to the corona restrictions"

Fig. 2 TPACK process—examples of categories and hindering codes 
and is therefore assigned to the outcomes theme. The relations among the codes are further discussed in the context of Q2.

The process theme was constructed from six categories: Learner individual characteristics (L), Teacher individual characteristics (T), Situation (Sit), Pedagogy $(P)$, Technology (Tech), and Content $(C)$. We were inspired by the TPACK framework, which defines technology, pedagogy, content, and the relationships among and between these components as constituting the core knowledge for good teaching with technology (Koehler \& Mishra, 2009). TPACK also

\section{Cognitive}

- Learning effectiveness - learning quality

- "Unfortunately I feel there has been a drop in learning quality ever since we moved to online learning. The teachers cannot achieve the same level, and I can't tell whether it's the teachers or the platform"

\section{Affective}

\section{- Learner interest}

- "The learning is really boring. The teachers mostly read from their presentation and there's not much interaction between students"

- "Classes sometimes become monotonous and don't fit the media"

\section{- Student achievement expectation}

- "Usually I am a 90+ student, but I doubt I'll do well in my courses this semester"

\section{- Student motivation}

- "I am sick of this and every day it's the same situation and I don't feel like learning anymore...it's highly disturbing and doesn't suit me."

\section{- Student anxiety}

- "They overload us at school as it is and the assumption that we have more time because we are all at home does not coincide with the anxiety surfacing during this period"

\section{Social}

\section{- Sense of community/connectedness}

- "Challenges - in courses we sit in small groups, making friends and getting closer"

\section{- Social}

- "I miss seeing my friends"

\section{Physical}

- Headache

- "Sitting in front of a computer for several hours...it gives me a headache"

- Tiredness

- "It's a tiring method"

Fig. 3 Cog-Aff-Soc-Phy outcomes-examples of categories and hindering codes 
conceptualizes the learner, the teacher and the situation as contexts across which the relationships between the components may play out differently (Koehler \& Mishra, 2009; Rosenberg \& Koehler, 2015). We further refined the teacher and learner categories based on Dörnyei's (2005) definition of individual differences as stable personal characteristics applicable to everyone, with systematic deviation from a normative blueprint. Figure 2 shows some examples of emerging hindering codes that were assigned to the TPCAK-process categories, together with supporting excerpts. In the situation category, for example, the three hindering codes allude to some form of situational disorder that "clutters" the students' schedules.

The outcomes theme was constructed from four categories: cognitive (Cog), affective (Aff), social (Soc), and physical (Phy). These outcome domains are typical in learning frameworks (e.g., physical education and sports, in Bailey, 2006). Figure 3 depicts some examples of such hindering codes. As the data were collected during the earlier stages of ERT-OL, the students could not yet report their actual achievement outcomes, but they did report diminished learning effectiveness. In terms of affective outcomes, the hindering codes that emerged-such as interest, expectancy and actual motivation-are well-known components of motivation (Dörnyei \& Ushioda, 2011). These codes suggest an overall decrease in motivation. One interesting example of a hindering code in the social category was the potentially impaired sense of community and connectedness, in line with the negativity of these two factors often mentioned in the online learning literature (Glisan \& Trainin, 2006).

Most of the hindering codes were process codes classified as TPACK-situation, pedagogy, technology and content (Fig. 4). Even among a cohort of education majors, the high frequency of perceived process-technical hindering elements, and especially of the more elusive process-pedagogical hindering elements, is an interesting sign of the rich, diverse views of learners who are completely aware of their educational process. The fact that students reported outcomes less frequently is

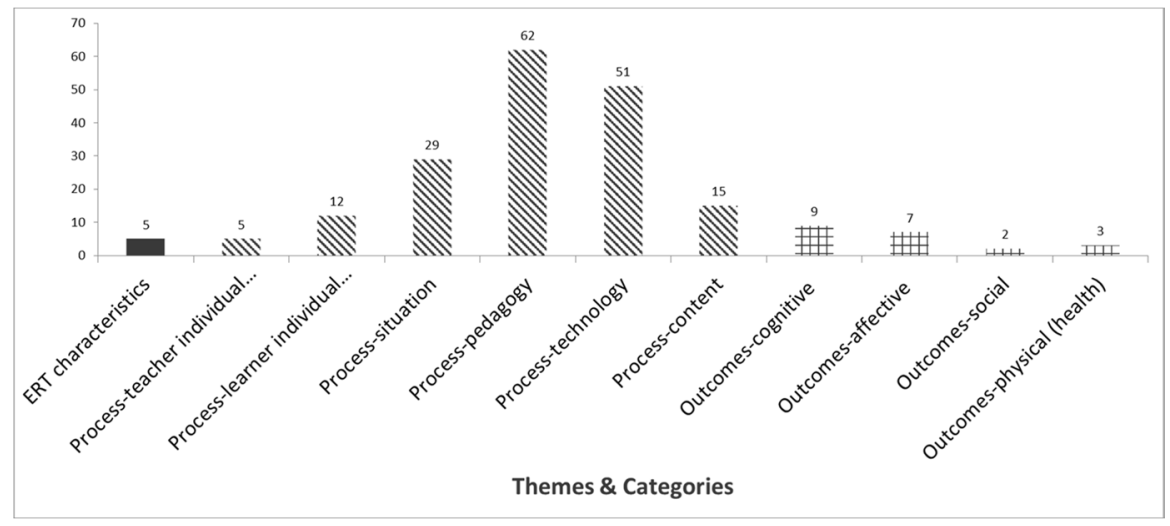

Fig. 4 ERT-LO—hindering codes per category (ERT characteristics—full color, process—stripes, outcomes-grid) 
not surprising, given that the survey was distributed relatively early in the semester. Moreover, the survey's tendency to tap into consciously available cognitions in the form of easily accessible reason-based explanations (Joffe, 2012) may also explain this imbalance.

The data suggest that the ERT-OL story is comprised of hindering process elements that lead to diminished outcomes. Thus, differences in students' TPACK processes result in different Cog-Aff-Soc-Phy outcomes. Next, we explore the relationships among and between the categories by examining hindering code relations. Since this study focused on the three equity factors, we zoomed in on relations considered to be especially critical in these cases.

\subsection{COVID-19-Impact of ERT-OL hindering elements on educational equity}

The equity analyses focused on the three factors-language, SES, and juggling involving a total of 46 hindering codes. In each analysis, we first selected hindering process codes relevant to the factor and then examined the related codes. Below, we highlight the problematic sub-themes discovered for these three factors within the overarching process-outcomes ERT-OL story and discuss the code categories and relations among and between them.

\subsubsection{Language factor: Intensified hindering (mediating and moderating) links}

The analysis began with five hindering codes that are related to the four language skills (reading, listening, writing, and speaking) and are also quite prevalent in the data: 1) chat; 2) class discussion; 3) class questions; 4) platform audio (sound); and 5) teacher speech speed - fast. This analysis was based on the premise that certain skills are required for language ability: reading and listening (receptive skills) and writing and speaking (productive skills) (Golkova \& Hubackova, 2014).

Table 1 shows some intra-category relations among the ERT-OL process-pedagogical codes uncovered during the language analysis, along with an excerpt from the students' supporting textual answers. The table shows that a large number of participants in an online class can hamper discussions. Furthermore, many simultaneous talkers who do not know when to join the discussion can obstruct learners' participation (the first two mediation paths). Glitches and delays in audio response due to the packet-switch technology behind video conversations can explain these conversational clashes (Johnson, 2020). Respondents noted the critical role of

Table 1 Language of instruction-intra-category pedagogy relations

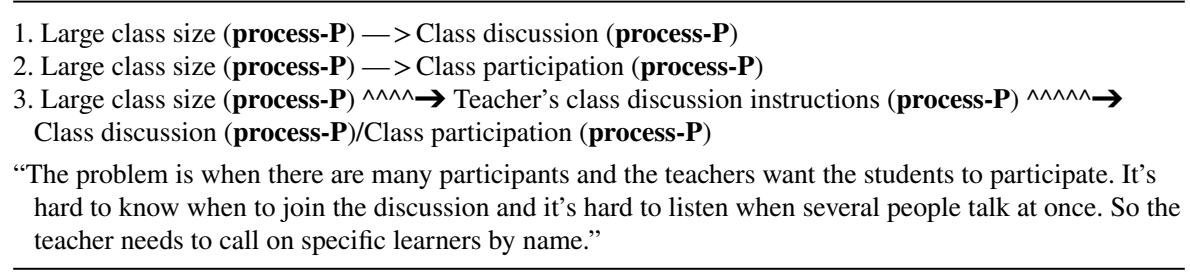

$\longrightarrow$ mediation; ${ }^{\wedge \wedge \wedge \wedge} \rightarrow$ moderation 
Table 2 Language of instruction-pedagogy and technology inter-category relations

1. Chat (process-Tech) ${ }^{\wedge \wedge \wedge \wedge} \rightarrow$ Learner microphone open (process-Tech( $(\wedge \wedge \wedge \wedge \rightarrow$ Class discussion (process-P)

"Difficulties in discussions. Sometimes it isn't clear whether the discussion is in the chat or with sound, leading to two parallel discussions"

2. Chat (process-Tech) ${ }^{\wedge \wedge \wedge \wedge} \rightarrow$ Learner microphone shut (process-Tech( ${ }^{\wedge \wedge \wedge \wedge} \rightarrow$ Class questions (process-P)

"When teachers ask a question, if they locked the option for students to speak, they need to wait and give us time to think and also to write the answer in the chat. Almost all the teachers ask questions and then after three seconds answer the questions themselves"

$\longrightarrow$ mediation; $\wedge \wedge \wedge \wedge \rightarrow$ moderation

teacher instructions for managing discussion and participation (the third moderation path). Other textual answers (not included here due to space limitation) demonstrate how the quality of online discussion, participation and question-raising may depend on clearer teacher instructions, regardless of class size. Since these faulty relations concern communicative skills, their negative effect is likely to increase for learners whose first language differs from the language of instruction.

Table 2 shows some of the emerging inter-category relations between ERT-OL technical and pedagogical codes. Simultaneous discussions can conflict when chat and microphone are both open in the live virtual classroom (Path 1). If microphones are turned off, students may also try to think and write in the chat as quickly as possible, before the teacher provides an answer (Path 2). This may be especially tricky for students whose language differs from the teaching language, given their justified concerns about grammatical and spelling mistakes (Krutka et al., 2020), to the point of genuine anxiety about writing in the second language (Cheng et al., 1999). Other textual answers suggest an imbalance between chats and questions. Thus, the chat is an inefficient channel for raising questions, given that teachers ignore it. Conversely, it is suggested that the chat function may invite an overflow of questions that can harm the class flow. The implications of all these relations are likely to be more harmful to non-native speakers.

Table 3 introduces the cognitive outcomes category and illustrates how the process codes and categories may lead to these outcomes. The process-technology

Table 3 Language of instruction-process and cognitive outcomes relations

1. Teacher internet connection quality (process-Tech) $\rightarrow$ Platform audio (sound) (process-Tech)

"Difficulties - mainly when the teacher's internet isn't stable and cannot be heard clearly"

2. Platform audio (sound) (process-Tech) $\longrightarrow>$ Student concentration/attention (outcomes-Cog)

"Sometimes the teacher cannot be heard well and so the students lose attention"

3. Platform audio (sound) (process-Tech) $\longrightarrow>$ Missed materials-learning effectiveness (outcomesCog)

"Sometimes there are technical problems so that students can't hear and thus miss material"

4. Platform audio (sound) (process-Tech) $\longrightarrow>$ Platform disconnection (process-Tech) $-\longrightarrow \longrightarrow$ Missed materials-learning effectiveness (outcomes-Cog)

"Sometimes the teacher's speech is intermittent, sometimes I only hear sentence fragments and I need to exit the virtual room and reenter to refresh the page"

$\longrightarrow$ mediation; $-\longrightarrow$ - $\rightarrow$ latent-mediation 
Table 4 Language of instruction-process, cognitive outcomes and cyclic relations

1. Class interaction with teacher (process-P) $\longrightarrow$ Teacher speech speed - fast (process-P)

"Sometimes the teacher talks too fast and it's difficult to report this"

2. Class interaction with teacher (process-P) $\longrightarrow>$ Teacher speech speed - fast (process-P) $\longrightarrow>$ Material comprehension-learning effectiveness (perception) (outcomes-Cog)

"Teachers explain things too fast because they can't read the class response at a given time. This makes understanding the material difficult"

3. Technical issues (process-Tech) $\longrightarrow$ Material comprehension-learning effectiveness (perception) $\left(\right.$ outcomes-Cog) ${ }^{\wedge \wedge \wedge} \rightarrow$ Teacher speech speed - fast (process-P) ${ }^{\wedge \wedge \wedge} \rightarrow$ Material comprehensionlearning effectiveness (perception) (outcomes-Cog)

"Teachers should be more aware that the class is online and occasionally there are issues and comprehension difficulties, so they need to slow down their speech and teaching pace a bit"

$\longrightarrow$ mediation; $\wedge \wedge \wedge \wedge \rightarrow$ moderation

category focused on the role of audio in online learning. The first path attributes audio problems to insufficient internet quality (discussed further in the socioeconomic analysis). The second path suggests that audio problems may lead to cognitive outcomes regarding concentration. The third path indicates that trouble hearing the audio can lead to skipped (non-learned) materials. The fourth path suggests that learners may disconnect from the virtual classroom when the audio is impaired and consequently miss learning materials (this latent-mediation part of the path was assumed based on researchers' inference, as it was not explicitly stated in the text). Other textual answers explain how audio problems, mediated through impaired class flow, may lead to a cognitive outcome of inadequate material comprehension. These audio implications may be experienced more intensely for learners whose first language differs from the language of instruction.

Table 4 shows the final language analysis and portrays the probable cyclic relations between process and outcomes. This analysis relied on statements alluding to teachers who spoke too fast during online learning. This may result from insufficient teacher-student interaction and lead to deficient material comprehension (Paths 1 and 2). The third path shows the probable cyclic relations. Insufficient understanding online (which may have various triggers) may be further intensified when teachers speak too quickly. Other textual answers revealed another interesting cyclic relation positing that inadequate comprehension of learned materials resulting from teachers talking too fast may force learners to review the lesson, consequently adding to the school workload. The latest research on COVID-19 online learning reflects similar issues, suggesting that teachers should slow down. These studies also indicate that restricted facial expressions and body language with sole reliance on voice make slowing down imperative (Bao, 2020). All these problems are likely to worsen when the fast speech is in a language that differs from the learners' native language.

\subsubsection{SES factor: Intensified hindering (mediating and moderating) links}

The SES analysis began with the following five hindering codes: 1) internet connection quality; 2) network overload; 3) learning environment interruptions; 4) learning 
Table 5 Socioeconomic-process and cognitive outcomes relations

1. Internet connection quality (process-Tech) $\rightarrow>$ Platform audio (sound) (process-Tech)- - - $\rightarrow$ Missed materials-learning effectiveness (outcomes-Cog)

"The internet disconnects quite often and I only hear fragments of things"

2. Network overload (process-Tech) $\longrightarrow>$ Platform audio (sound) (process-Tech) $\rightarrow$ Class flow (process-P)

"Sometimes the lesson is intermittent due to overload. The teacher's speech is intermittent and the lesson flow is disrupted"

3. Internet connection quality (process-Tech) $\longrightarrow>$ Platform audio (sound) (process-Tech) $\longrightarrow>$ Class discussion (process-P)

"Having conversations is challenging because of the response delay"

$\longrightarrow$ mediation; - - - $\rightarrow$ latent-mediation

environment noise; and 5) computers and other equipment at home. The first two codes (for this qualitative study, we did not merge similar codes) and the last one relied on the digital divide assumption, which associates lower income with inadequate technology access (Alam, 2020; Alipio, 2020; Collin \& Brotcorne, 2019; Girik Allo, 2020; Livingstone \& Helsper, 2007; Tsetsi \& Rains, 2017). The third and fourth codes were based on premises linking lower income with lower residential environmental quality, such as lack of privacy, chaos and noise (Dilworth-Bart, 2012; Evans, 2004; Evans \& Kantrowitz, 2002; Joo \& Lee, 2020). Moreover, these specific codes were quite prevalent in the data.

Table 5 reveals the first findings of the SES analysis that illuminate relations between process and cognitive outcomes. Inadequate internet quality can lead to bad audio quality (Path 1), which in turn can reduce cognitive outcomes in terms of concentration, comprehension and omission of materials, as discussed above with respect to language. Similarly to language, faulty audio may then hamper class flow (Path 2), which, based on the previous language analysis, can further lead to inadequate comprehension. Low connection quality can also hamper discussions due to delays in audio response (Path 3). Not only do audio delays and glitches typical of video conversations lead to conversational clashes (also noted in the language analysis), they have also been linked to reduced trustworthiness and the need to exert extra effort to compensate for delays (Johnson, 2020). Given the delay in feedback, people may avoid sharing a "good story" because they feel it would go unrewarded (Murphy, 2020). Other textual answers point to poor

Table 6 Socioeconomic_-introducing the process-situation category

1. Learner microphone open (process-Tech) ${ }^{\wedge \wedge \wedge \wedge} \rightarrow$ Learning environment noise (process-Sit) ${ }^{\wedge \wedge \wedge \wedge \rightarrow ~}$ Class noise (process-P)

"Everyone has background noise at home, so it's best that everyone turn off their microphones"

2. Learning environment noise (process-Sit) $\longrightarrow$ Class noise (process-P) $\longrightarrow>$ Learner microphone shut (process-Tech) $\longrightarrow$ Class participation (process-P)

"The noise at home also interrupts the people in the class and then we are forced to turn off our microphones and not take part"

$\longrightarrow$ mediation; $\wedge \wedge \wedge \wedge \rightarrow$ moderation 
Table 7 Socioeconomic_-introducing physical outcomes

1. Computers and other equipment at home (process-Tech) - - - $\rightarrow$ Missed materials-learning effectiveness (outcomes-Cog)

"There's a shortage of computers, including headsets, mouse etc."

2. Computers and other equipment at home (process-Tech) $\wedge^{\wedge \wedge \wedge} \rightarrow$ Student class timetable intensity (process-Sit) ${ }^{\wedge \wedge \wedge} \rightarrow$ Student (physical) health - eyes (outcomes-Phy)

"I don't have a computer so I study on an old, slow phone and my eyes really get tired from viewing and using the phone continuously for seven hours"

- - - $\rightarrow$ latent-mediation; $\wedge \wedge \wedge \wedge \rightarrow$ moderation

internet connection quality that can go as far as halting a class, presumably causing learned materials to be missed. In addition, low-quality internet may disrupt viewing a class recording, likely necessitating repeated viewing and increasing school workload. These faulty connections are inevitable for those with low SES who are likely to have poor internet quality.

Table 6 focuses on the process-situation category. When learners study under noisy conditions (situation code) opening microphones in a virtual classroom can become quite noisy as well (Path 1). Yet other learners complained about having to turn off their microphones due to noise at home, preventing them from participating (Path 2). Other textual answers show that in terms of cognitive outcomes, a noisy learning environment can hamper students' attention and overall learning quality. Thus the ERT-OL experience may be diminished for students from lower socioeconomic backgrounds who lack a serene home environment.

The outcomes shown in Table 7 stem from the equipment analysis. Inadequate computer equipment may presumably cause students to miss materials due to their inability to connect (Path 1). The second path introduces physical outcomes, among them the long study duration using a mobile phone, leading to tired eyes and overall fatigue. This finding is in line with earlier literature indicating that small-screen-size mobile learning is most suitable for shorter learning sessions and smaller chunks of information (Feser, 2014). Thus, among those in lower SES strata with inadequate equipment, negative outcomes may increase.

\subsubsection{Juggling factor: Intensified hindering (mediating and moderating) links}

Based on the above literature on parents and working students, we selected student parenthood and student workload as codes to start the juggling analysis. These codes were also highly prevalent in the data. Tables 8,9 , and 10 present the findings from the juggling analysis, respectively showing how cognitive outcomes related to concentration, missed materials and school workload may be intensified for jugglers.

Table 8 suggests a reduced degree of concentration among parenting students while their kids are at home (Path 1). The process-learner category also surfaced at this point. Concentration seems to be a problem for anyone who sits in front of a computer screen for extended periods (Path 2). This finding is consistent with recent reports about the unwanted outcomes of videoconferencing platforms. Accordingly, fatigue and deteriorated concentration develop as people work harder to process 
Table 8 Juggling parents — cognitive outcomes in concentration

1. Student parenthood (process-L) $\longrightarrow>$ Student concentration/attention (outcomes-Cog)

"The main problem is studying at home...the children are in the background and it's really not simple to concentrate and figure out the demands"

2. Student class timetable intensity (process-Sit) $\longrightarrow>$ Computer screen exposure time (process-Tech) $\longrightarrow$ Student concentration/attention (outcomes-Cog)

"Online lessons should be shorter than an hour and a half. It's super difficult to sit in front of a computer and concentrate for an hour and a half and do it repeatedly five days a week"

3. Student class timetable intensity (process-Sit) $\longrightarrow$ Computer screen exposure time (process-Tech) $\wedge \wedge \wedge \wedge \rightarrow$ Student parenthood (process-L) ${ }^{\wedge \wedge \wedge} \rightarrow$ Student concentration/attention (outcomes-Cog)

"It's tough to sit in front of the computer for hours (8:00 am until 8:00 pm) and maintain attention and concentration while kids are home at the same time - it becomes a highly complicated, almost impossible mission"

$\longrightarrow$ mediation; $\wedge \wedge \wedge \wedge \rightarrow$ moderation

non-verbal cues. Moreover, people's awareness of the open camera may also drain their resources (Jiang, 2020). Thus, parents with children at home may lose their concentration faster when exposed to screens for protracted periods (Path 3). Other textual answers indicate that a self-disciplined parent-student can, however, mitigate this concentration effect. Other studies have similarly demonstrated the important role of self-regulation, including self-discipline, in online learning (Kauffman, 2015). In addition, teachers who pay attention to their students' circumstances can also help them focus, possibly by shortening the duration of online lessons. Note that parent-students with children at home and a nosier learning environment may also, as discussed in the SES analysis, contribute to online class noise when their microphones are opened, forcing them to turn off their microphones and refrain from participating.

Table 9 pertains to the cognitive risks of missed learned materials among parentstudents. Regularly scheduled classes may conflict with childcare demands because the schools are closed due to COVID-19 (Path 1). Regular hours have been reported as problematic even during "normal" times (Gillett-Swan, 2017). Thus, an extended class schedule is more likely to result in missed materials for parents (Path 2). The children's age is also a factor, with younger children leading to higher rates of missed materials (Path 3). Therefore, attending a class at its scheduled time or conforming to an extended study schedule may be more challenging for students with younger children (Paths 4 and 5). The textual answers also indicate that the problem of missing classes can be alleviated if parents receive assistance at home with their children. Parents who struggle alone to care for their children and keep up with their studies can develop negative feelings and emotions. This also illustrates how affective outcomes can emerge in this meshed framework. Moreover, during regularly scheduled classes or when the study timetable is dense, some parents may need to "compete" with their children for computer equipment and thus likely to miss more materials. A shortage of equipment, especially during COVID-19, is not necessarily a sign of lower SES as even in families from advantaged backgrounds, laptops are not always available for each family member ("Coronavirus: Laptops \& 4G Internet 
Table 9 Juggling parents-missed materials cognitive outcomes

1. Regular class hours (process-Sit) ${ }^{\wedge \wedge \wedge} \rightarrow$ Student parenthood (process-L) ${ }^{\wedge} \wedge \wedge \wedge$ Missed materialslearning effectiveness (outcomes-Cog)

"Remote learning in real-time is not practical in my case. I cannot make time at a set hour and day due to staying at home with the children"

2. Student class timetable intensity (process-Sit) $\wedge^{\wedge \wedge \wedge} \rightarrow$ Student parenthood (process-L) ${ }^{\wedge \wedge \wedge \wedge \rightarrow ~}$ Missed materials-learning effectiveness (outcomes-Cog)

"It is difficult for me to make time for so many hours with three children at home"

3. Student young children (process-L) $\longrightarrow>$ Miss materials—learning effectiveness (outcomes-Cog)

"Online learning presents many challenges in the current situation when the children are also at home and especially the little ones who require that I be present and watch over them"

4. Regular class hours (process-Sit) $\wedge^{\wedge \wedge \wedge} \rightarrow$ Student young children (process-L) ( $^{\wedge} \rightarrow \rightarrow$ Miss materials-learning effectiveness (outcomes-Cog)

"As a mother of three kindergarten to elementary-school-age children who are of course at home, I must deal with many difficulties to be able to participate in the synchronous classes in terms of my daily schedule at home"

5. Student class timetable intensity (process-Sit) $\wedge^{\wedge} \wedge \rightarrow$ Student young children (process-L) $)^{\wedge \wedge \wedge} \rightarrow$ Missed materials-learning effectiveness (outcomes-Cog)

"My main difficulty is that I have young children, while my teachers expect me to stay in front of the computer for a whole day. I can't be in front of the computer from 8:30 am to 7:45 pm when I have two little ones at home"

$\longrightarrow$ mediation; $\wedge \wedge \wedge \wedge \wedge \rightarrow$ moderation

Offered to School Pupils", 2020). For these parents, missing classes may be alleviated if recordings are made available on time.

Finally, Table 10 shows how a cognitive outcome of heavier school workload may develop among parenting-students or working-students. School workload induced by increased task capacity in ERT-OL may prevail among the general student body (Path 1). These findings are in line with previous studies suggesting that students spend much more time learning online than face-to-face and do not perceive this positively (Soffer \& Nachmias, 2018). For parents who must care for their children at home (Path 2), school workload may further intensify (Path 3). Some students complained that the curricular demands were not reduced and sometimes were even expanded, burdening parents with even heavier workloads. In addition, juggling

Table 10 Juggling-parents/employed students—school workload cognitive outcomes

1. Offline tasks (process-P) $\longrightarrow>$ School workload (outcomes-Cog)

"It seems like teachers think that online learning isn't sufficient and therefore they overload us with assignments"

2. Student parenthood (process-L) $\longrightarrow>$ Student house workload (process-Sit)

"We are now working $24 \times 7$ with the children at home and our load is multiplying"

3. Offline tasks (process-P) ${ }^{\wedge \wedge \wedge} \rightarrow$ Student parenthood (process-L) ${ }^{\wedge \wedge} \wedge \wedge \rightarrow$ School workload (outcomesCog)

"As a mother of children who are of course at home, I am having serious trouble completing the weekly assignments"

$\longrightarrow$ mediation; $\wedge \wedge \wedge \wedge \rightarrow$ moderation 
working-parents are likely to experience an even heavier school workload when tasks or school demands increase. School workload may be emotionally counter-productive, leading to feelings such as stress, thus exemplifying the links between cognitive and affective outcomes. School workload may also build up among working students who are unable to summarize a class mediated through an incompatible videoconferencing system, thus requiring them to review the lesson despite their time constraints.

To conclude our discussion of Q2, we also highlight two interesting points about all three analyses. First, some of the hindering codes emerged in more than one analysis, suggesting that problematic areas can be shared by different equity factors. For example, the need to review the lesson, which increased school workload, emerged in all three factors, although the reasons differed. Second, some hindering codes are relevant only to the COVID-19 quarantine conditions, such as jugglingparent codes concerning noise at home, equipment shortages and inability to attend regularly scheduled classes. We define these as contextual hindering codes. Furthermore, whereas some hindering codes are fixed ERT characteristics (such as studying at home), during "normal" times they may become variables signaling variance between learners.

\subsubsection{Narrative summary}

The previous tables disclose a narrative typical of groups of learners. The narrative raises some critical issues for learners whose first language differs from the language of instruction. First, issues related to in-class synchronous interaction, such as flawed discussions, participation and raising questions (pedagogy processes), may be especially critical for this population. Second, issues related to in-class synchronous chat that pose problems for learners in general, such as question overflow, teacher ignorance, parallel written and oral discussions and rapid response (pedagogy processes), are more challenging for non-native speakers. Third, issues related to in-class synchronous audio are problematic in online learning in that they may hamper concentration, lead to skipped materials, and impair material comprehension (cognitive outcomes). These issues may be more harmful for non-native language speakers. Finally, issues of teachers' synchronous and rapid talk in-class have been reported by learners, leading to task overload and impaired material comprehension (cognitive outcomes). These issues may pose particular problems for non-native speakers.

Students from lower socioeconomic backgrounds may have to contend more frequently with lower internet quality. This factor is crucial in that it may disrupt class discussion and flow (pedagogy processes) and may diminish students' concentration, impair their comprehension, and lead to skipped materials and task overload (cognitive outcomes). A noisy home environment, which may be especially prevalent among students with low SES, can diminish learning quality and reduce concentration (cognitive outcomes). Inadequate technological equipment, which is particularly likely for students with low SES, can lead to skipped materials (cognitive outcomes) and diminished eyesight (physical outcomes).

The narrative of juggling parents suggests that reduced concentration is a stumbling block for these students (cognitive outcomes). This problem is prevalent among everyone who must spend long periods of time facing screens, and especially for those 
with children at home and who lack self-discipline. The juggling parents narrative also suggests a high likelihood of missed learned materials (cognitive outcomes), as regularly scheduled classes may conflict with childcare responsibilities due to school shutdowns. This is especially critical for fulltime students who must care for young children with no assistance at home, while "competing" with children for access to equipment. Finally, the narrative of juggling parents or workers implies a heavy school workload (cognitive outcomes). This problem is evident for anyone in ERT-OL faced with increased task capacity, expanded school demands or the need to review lessons due to problems with learning platforms. The problem is particularly critical among working students, parents caring for children at home, or working parents. In view of these difficulties, it is interesting to examine some possible mitigating strategies.

\subsubsection{Mitigating strategies}

To conclude the overall discussion, we would like to point that although this paper discusses the hindering elements of ERT-OL, the seeds of positive elements can also be extracted from the data to deduce strategies to mitigate these learning barriers, as implied by the findings. For example, when we examine elements that hinder ERTOL during COVID (Q1), we find that group work difficulties (Fig. 2) suggest that individual work rather than group work should be permitted in ERT-OL during the pandemic. The lack of a sense of community or connectedness and social difficulties in general (Fig. 3) imply that social interaction between students should be facilitated in ERT-OL.

In examining the hindering elements with respect to language, SES, and juggling educational equity factors (Q2), we learn for example that chat problems (Table 2) can be mitigated by a teaching assistant who can monitor the chat when teachers are talking online. Rapid speech on the part of teachers (Table 4) calls for instructing teachers to speak slower online. Students who must review lessons due to platform disconnection, thus increasing school workload (Table 5), is yet another signal of why online synchronous instruction should be kept to short episodes (Smith, 2020). Late recording upload timing (after class) implies that policy is needed to promote the availability of recordings to students within a reasonable amount of time. School workload (Table 10) calls for minimizing student workload during ERT-OL by limiting the number of courses. More seeds of such positive elements may surface through further thoughtful examination of the hindering elements in order to overcome deficit thinking that is clearly detrimental (Dudley-Marling, 2015; Heinbach et al., 2019).

\section{Conclusions}

This study sought to listen to university students during the early stages of ERTOL. The themes emerging from the thematic analyses of 154 open-textual items expressing students' perceived difficulties constructed the story of ERTOL. This story involved different hindering elements that signal possible variances between learners. The elements collected under the TPACK process led to 


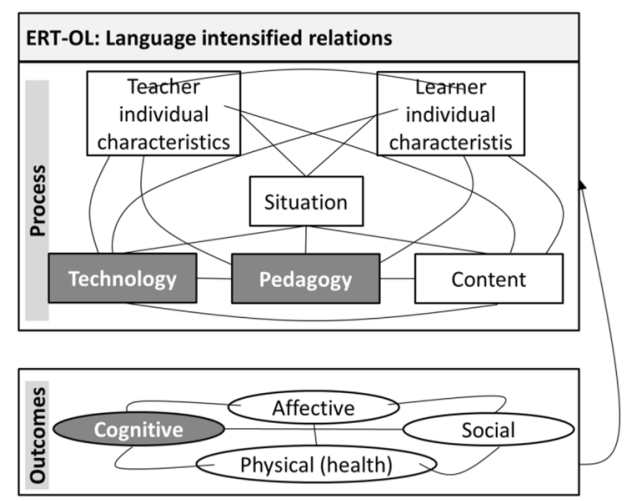

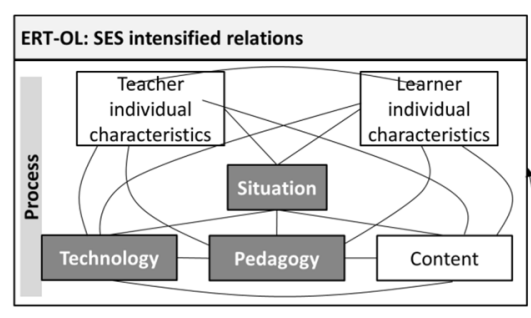

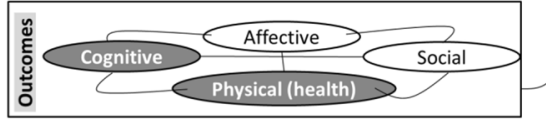

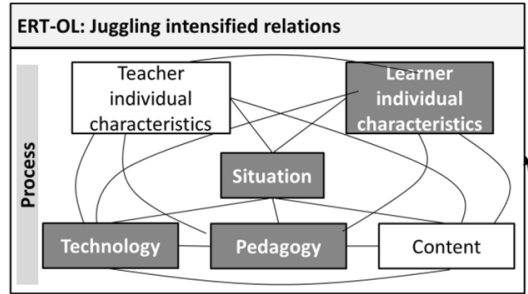

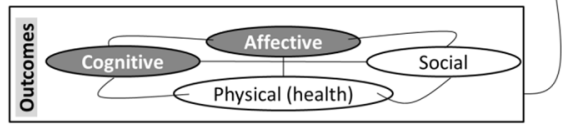

Fig. 5 ERT-OL process and outcomes maps of equity factors

Cognitive-Affective-Social-Physical outcomes (with a few hindering elements themed as ERT characteristics, suggesting similarities between learners). Thus, differences between learners can be examined through divergent TPACK-processes and their consequent different outcomes.

We delved into the relationships among and between the TPACK process and the Cog-Aff-Soc-Phy outcomes by inspecting specific codes related to language, SES and juggling equity factors, while gradually introducing the various categories. These three analyses revealed a mesh of intricate mediating/moderating and cyclical relationships. We thus showed how, when equity factors are considered, hindering links (constructed of hindering elements) can become more acute, leading to further decreases in process and outcomes. The process and outcomes map (Fig. 5) and its underlying equity-intensified relations support and explain general claims that the crisis has disproportionately affected the most vulnerable students, as evidenced by their physical, mental and academic outcomes (Reich et al., 2020).

\subsection{Contribution}

Scholars have discussed both the challenges of online learning in higher education and the relationships between these challenges, albeit less explicitly (e.g., 
Gillett-Swan, 2017; Islam et al., 2015). This study advances knowledge about ERTOL hindering elements and their relations during the COVID-19 crisis. The comprehensive process-outcomes relationships map can help in understanding the hindering elements and their relationships in general, and particularly from an equity standpoint. Interested researchers can use this map as a comprehensive research framework to provide systematic guidance in further analyzing students' ERT-OL difficulties, while considering various equity factors on the way to uncovering hindering elements and revealing latent relationships. Students' elaborated awareness of the process in addition to the outcomes, as exemplified in the richness of their perceived hindering pedagogical and technical process elements, encourages researchers to adopt a systematic approach in this field. Shedding light on ERT-OL may also project onto subsequent "normal" periods, during which contextual hindering elements or ERT characteristics are likely to change.

In designing or evaluating ERT-OL courses for contemporary pandemics or other crises, university faculty can use this map as an inclusive teaching framework that can help in understanding hindering elements and their relations. In subsequent "normal" times, faculty can use the map while revisiting contextual hindering elements (e.g., juggling parents, studying at regularly scheduled hours, noisy home environments and sharing equipment with children) and ERT characteristics (e.g., studying from home), as these are most likely to change.

In meeting the needs of special populations (Reich et al., 2020), faculty can zoom in on the process-outcomes map based on equity factors to identify acute problematic areas for specific diverse groups of interest, in line with the literature contending that both inputs and outcomes must be considered when evaluating equity in education (The Aspen Education \& Society Program \& the Council of Chief State School Officers, 2017). Knowledgeable faculty members can deal with the inequity in higher education revealed and exacerbated by the pivotal shift to ERT-OL during the current pandemic (Maloney \& Kim, 2020). For example, in this study we chose language, SES and juggling factors, which are typical of Israeli academic culture. Other places can apply this idea based on their most acute educational equity factors. Problematic areas shared by several equity factors can be uncovered. In our study, we found that given language and SES factors, audio problems leading to missed materials were likely. Increased school workload was problematic for all three factors, although for different reasons. Finally, in dealing with hindering elements faculty members should consider the relevant mitigating strategies, as demonstrated by some elements found in this study.

\subsection{Limitations and future studies}

This qualitative, open-ended question study was based on 154 data items. Extensive quantitative surveys are needed to further validate the relationships among the hindering elements and the map categories. Process and outcomes hindering elements should be converted to operational variables. In Israel, for example, a national crossuniversity survey is currently underway. Other places can track hindering elements and equity factors as appropriate. ERT-OL is undergoing significant improvements. 
Therefore, it would be beneficial to begin examining achievement outcomes as well. In the more distant future when things get back to "normal", contextual hindering elements should be reconsidered. Moreover, experimental studies should tap into map links and check for causality (e.g., effects of online speech speed or audio quality on comprehension and concentration).

Acknowledgements Not applicable

Authors contributions section All authors were involved in this research as well as in the writing process.

Funding Not applicable.

Data availability Data will be supplied upon request.

\section{Declarations}

Ethics approval and consent to participate This research received the Institutional Review Board (IRB) approval.

Consent for publication The manuscript does not contain any individual person's data in any form.

Competing interests No conflict of interest is reported by the authors.

\section{References}

Abbott-Chapman, J., Braithewaite, J., \& Godfrey, J. (2004). Promoting access, increasing opportunities for university education: A study of mature aged students from disadvantaged regions. Commonwealth of Australia Department of Education, Science and Training. https://www.researchgate.net/ publication/267335101.

Alam, A. (2020). Challenges and possibilities of online education during Covid-19. Preprints 2020. https://doi.org/10.20944/PREPRINTS202006.0013.V1.

Alipio, M. M. (2020). Education during COVID-19 era: Are learners in a less-economically developed country ready for e-learning? ZBW - Leibniz Information Centre for Economics. https://did.li/ iaJw5.

Altbach, P. G., \& De Wit, H. (2020). Are we at a transformative moment for online learning? University World News. https://www.universityworldnews.com/post.php?story=20200427120502132.

Aparicio, M., Bacao, F., \& Oliveira, T. (2016). An e-Learning theoretical framework. Journal of Educational Technology \& Society, 19(1), 292-307.

Ezra, O., Cohen, A., Bronshtein, A., Gabbay, H., \& Baruth, O. (2021, March). Critical success factors of distance online learning in higher education during COVID-19: differences among students. In Society for Information Technology \& Teacher Education International Conference (pp. 12181225). Association for the Advancement of Computing in Education (AACE).

Bailey, R. (2006). Physical education and sport in schools: A review of benefits and outcomes. Journal of School Health, 76(8), 397-401. https://doi.org/10.1111/j.1746-1561.2006.00132.x.

Bao, W. (2020). COVID-19 and online teaching in higher education: A case study of Peking University. Human Behavior and Emerging Technologies, 2(2), 113-115. https://doi.org/10.1002/hbe2.191.

Braun, V., \& Clarke, V. (2006). Using thematic analysis in psychology. Qualitative Research in Psychology, 3(2), 77-101. https://doi.org/10.1191/1478088706qp063oa.

Braun, V., \& Clarke, V. (2012). Thematic analysis. In H. Cooper (Editor-in-Chief), P. Camic, K. Sher, A. T. Panter, D. Long, \& D. Rindskopf (Eds.), APA handbook of research methods in psychology, Vol 2: Research designs: Quantitative, qualitative, neuropsychological, and biological. (pp. 57-71). American Psychological Association. https://doi.org/10.1037/13620-004. 
Brooks, R. (2012). Student-parents and higher education: A cross-national comparison. Journal of Education Policy, 27(3), 423-439. https://doi.org/10.1080/02680939.2011.613598.

Bühmann, D., \& Trudell, B. (2008). Mother tongue matters: Local language as a key to effective learning. UNESCO. http://unesdoc.unesco.org/images/0016/001611/161121e.pdf.

Cheng, Y. S., Horwitz, E. K., \& Schallert, D. L. (1999). Language anxiety: Differentiating writing and speaking components. Language Learning, 49(3), 417-446. https://doi.org/10.1111/0023-8333. 00095.

Collin, S., \& Brotcorne, P. (2019). Capturing digital (in)equity in teaching and learning: A sociocritical approach. International Journal of Information and Learning Technology, 36(2), 169-180. https:// doi.org/10.1108/IJILT-05-2018-0059.

Conole, G., Dyke, M., Oliver, M., \& Seale, J. (2004). Mapping pedagogy and tools for effective learning design. Computers \& Education, 43(1-2 SPEC ISS.), 17-33. https://doi.org/10.1016/j.compedu. 2003.12.018.

Coronavirus: Laptops and 4G internet offered to school pupils. (2020). BBC News. https://www.bbc.com/ news/uk-wales-politics-52478688.

Dilworth-Bart, J. E. (2012). Does executive function mediate SES and home quality associations with academic readiness? Early Childhood Research Quarterly, 27(3), 416-425. https://doi.org/10. 1016/j.childyouth.2020.105617.

Dörnyei, Z. (2005). The Psychology of the language learner: Individual differences in second language acquisition. Routledge. https://doi.org/10.4324/9781410613349.

Dörnyei, Z., \& Ushioda, E. (2011). Teaching and researching motivation. Routledge. https://doi.org/10. 4324/9781315833750.

Dudley-Marling, C. (2015). The Resilience of Deficit Thinking. Journal of Teaching and Learning, 10(1). https://doi.org/10.22329/jtl.v10i1.4171.

Evans, G. W. (2004). The environment of childhood poverty. American Psychologist, 59(2), 77-92. https://doi.org/10.1037/0003-066X.59.2.77.

Evans, G. W., \& Kantrowitz, E. (2002). Socioeconomic status and health: The potential role of environmental risk exposure. Annual Review of Public Health, 23, 303-331. https://doi.org/10.1146/annur ev.publhealth.23.112001.112349.

Feser, J. (2014). mLearning Is not e-Learning on a mobile device. In C. Udell \& G. Woodill (Eds.), Mastering mobile learning (pp. 35-42). Wiley. https://doi.org/10.1002/9781119036883.ch5..

Gillett-Swan, J. (2017). The challenges of online learning: Supporting and engaging the isolated learner. Journal of Learning Design, 10(1), 20-30. https://doi.org/10.5204/jld.v9i3.293.

Girik Allo, M. D. (2020). Is the online learning good in the midst of Covid-19 Pandemic? The case of EFL learners. Jurnal Sinestesia, 10(1), 1-10.

Glisan, E., \& Trainin, G. (2006). Online community and connectedness. Research and Evaluation in Literacy and Technology, 7. Retrieved from https://digitalcommons.unl.edu/cehsgpirw/7.

Golkova, D., \& Hubackova, S. (2014). Productive skills in second language learning. Procedia - Social and Behavioral Sciences, 143, 477-481. https://doi.org/10.1016/j.sbspro.2014.07.520.

Hall, R. (2010). The work-study relationship: Experiences of full-time university students undertaking part-time employment. Journal of Education and Work, 23(5), 439-449. https://doi.org/10. 1080/13639080.2010.515969.

Hannon, J., \& D’Netto, B. (2007). Cultural diversity online: Student engagement with learning technologies. International Journal of Educational Management, 21(5), 418-432. https://doi.org/10. 1108/09513540710760192.

Heinbach, C., Paloma Fiedler, B., Mitola, R., \& Pattni, E. (2019). Dismantling deficit thinking: A strengths-based inquiry into the experiences of transfer students in and out of academic libraries. In the Library with the Lead Pipe. http://www.inthelibrarywiththeleadpipe.org/2019/disma ntling-deficit-thinking/.

Hodges, C., Moore, S., Lockee, B., Trust, T., \& Bond, A. (2020). The difference between emergency remote teaching and online learning. Educause. Retrieved from https:/er.educause.edu/articles/ 2020/3/the-difference-between-emergency-remote-teaching-and-online-learning.

Hovdhaugen, E. (2013). Working while studying: The impact of term-time employment on dropout rates. Journal of Education and Work, 28(6), 631-651. https://doi.org/10.1080/13639080.2013. 869311.

Iddings, A. C. D. S. (2005). Linguistic access and participation: English language learners in an English-dominant community of practice. Bilingual Research Journal, 29(1), 165-183. https://doi. org/10.1080/15235882.2005.10162829. 
Islam, N., Beer, M., \& Slack, F. (2015). E-learning challenges faced by academics in higher education. Journal of Education and Training Studies, 3(5), 102-112.

Jiang, M. (2020). The reason Zoom calls drain your energy. BBC Worklife. https://www.bbc.com/ worklife/article/20200421-why-zoom-video-chats-are-so-exhausting.

Joffe, H. (2012). Thematic analysis. In D. Harper \& A. R. Thompson (Eds.), Qualitative research methods in mental health and psychotherapy (pp. 209-223). Wiley. https://doi.org/10.1002/ 9781119973249.ch15.

Johnson. (2020). Why Zoom meetings are so dissatisfying. The Economist. https:/www.economist. com/books-and-arts/2020/05/16/why-zoom-meetings-are-so-dissatisfying?fsrc=scn/fb/te/pe/ed/ \&fbclid=IwAR3clhkkzk1jy1FZAo9ZiJlQfRulMs8SY-LkJSw9eH4s41iqf0mJBvtJ92Y.

Joo, Y. S., \& Lee, W. K. (2020). Does living in a chaotic home predict adolescent delinquency? A moderated mediation model of impulsivity and school connectedness. Children and Youth Services Review, 119. https://doi.org/10.1016/j.childyouth.2020.105617.

Kauffman, H. (2015). A review of predictive factors of student success in and satisfaction with online learning. Research in Learning Technology, 23. https://doi.org/10.3402/rlt.v23.26507.

Keengwe, J., Diteeyont, W., \& Lawson-Body, A. (2012). Student and instructor satisfaction with E-learning tools in online learning environments. International Journal of Information and Communication Technology Education, 8(1), 76-86. https://doi.org/10.4018/jicte.2012010108.

Koehler, M. J., \& Mishra, P. (2009). What is technological pedagogical content knowledge? Contemporary Issues in Technology and Teacher Education, 9(1), 60-70.

Kramer, A., \& Kramer, K. Z. (2020). The potential impact of the Covid-19 pandemic on occupational status, work from home, and occupational mobility. Journal of Vocational Behavior, 119. https:// doi.org/10.1016/j.jvb.2020.103442.

Krutka, D. G., Seitz, R. Z., \& Hadi, A. M. (2020). How do we oppose racist Zoombombs?: A discriminatory design technology audit. In R. E. Ferdig, E. Baumgartner, R. Hartshorne, R. Kaplan-Rakowski, \& C. Mouza (Eds.), Teaching, technology, and teacher education during the COVID-19 pandemic: Stories from the field (pp. 753-759). Association for the Advancement of Computing in Education (AACE).

Lall, S., \& Singh, N. (2020). COVID-19: Unmasking the new face of education. International Journal of Research in Pharmaceutical Sciences, 11(Special Issue 1), 48-53. https://doi.org/10.26452/ ijrps.v11iSPL1.2122.

Lave, J., \& Wenger, E. (1991). Situated learning: Legitimate peripheral participation. Cambridge University Press.

Levin, T., \& Shohamy, E. (2008). Achievement of immigrant students in mathematics and academic Hebrew in Israeli school: A large-scale evaluation study. Studies in Educational Evaluation, 34(1), 1-14. https://doi.org/10.1016/j.stueduc.2008.01.001.

Livingstone, S., \& Helsper, E. (2007). Gradations in digital inclusion: Children, young people and the digital divide. New Media \& Society, 9(4), 671-696. https://doi.org/10.1177/1461444807080335.

Maloney, E. J., \& Kim, J. (2020). The challenge of equity in higher education under COVID-19: The first of three emergent themes. Inside Higher Ed. https://www.insidehighered.com/blogs/learning-innov ation/challenge-equity-higher-education-under-covid-19.

Maxwell, J. A., \& Miller, B. A. (2008). Categorizing and connecting strategies in qualitative data analysis. In S. N. Hesse-Biber \& P. Leavy (Eds.), Handbook of emergent methods (pp. 461-477). Guilford Press.

Moore, J. L., Dickson-Deane, C., \& Galyen, K. (2011). E-Learning, online learning, and distance learning environments: Are they the same? Internet and Higher Education, 14(2), 129-135. https://doi. org/10.1016/j.iheduc.2010.10.001.

Murphy, K. (2020). Why Zoom is terrible. The New York Times. https://www.nytimes.com/2020/04/29/ sunday-review/zoom-video-conference.html.

Reich, J., Buttimer, C. J., Fang, A., Hillaire, G., Hirsch, K., Larke, L., Littenberg-Tobias, J., Moussapour, R., Napier, A., Thompson, M., \& Slama, R. (2020). Remote learning guidance from state education agencies during the COVID-19 pandemic: A first look. Massachusetts Institute of Technology, MIT Teaching Systems Lab. https://osf.io/k6zxy/.

Rosenberg, J. M., \& Koehler, M. J. (2015). Context and technological pedagogical content knowledge (TPACK): A systematic review. Journal of Research on Technology in Education, 47(3), 186-210. https://doi.org/10.1080/15391523.2015.1052663. 
Santhanam, L. (2020). 'This is not working.' Parents juggling jobs and child care under COVID-19 see no good solutions. PBS NewsHour. https://www.pbs.org/newshour/health/this-is-not-working-paren ts-juggling-jobs-and-child-care-under-covid-19-see-no-good-solutions.

Smith, B. (2020). Feel drained after a year of Zoom meetings? There's brain science behind that fatigue. $A B C$ News. https:/www.abc.net.au/news/science/2020-12-18/zoom-meetings-video-calls-brainfatigue-neuroscience-attention/12974106.

Soffer, T., \& Nachmias, R. (2018). Effectiveness of learning in online academic courses compared with face-to-face courses in higher education. Journal of Computer Assisted Learning, 34(5), 534-543. https://doi.org/10.1111/jcal.12258.

Terry, G., Hayfield, N., Clarke, V., \& Braun, V. (2017). Thematic analysis. In C. Willig \& W. S. Rogers (Eds.), The SAGE handbook of qualitative research in psychology (pp. 17-37).

The Aspen Education \& Society Program and the Council of Chief State School Officers. (2017). Leading for equity: Opportunities for state education chiefs. https://ccsso.org/sites/default/files/2018-01/ LeadingforEquity_011618.pdf.

Tsay, C. H. H., Kofinas, A., \& Luo, J. (2018). Enhancing student learning experience with technologymediated gamification: An empirical study. Computers \& Education, 121, 1-17. https://doi.org/10. 1016/j.compedu.2018.01.009.

Tsetsi, E., \& Rains, S. A. (2017). Smartphone Internet access and use: Extending the digital divide and usage gap. Mobile Media \& Communication, 5(3), 239-255. https://doi.org/10.1177/2050157917 708329.

Vaismoradi, M., Jones, J., Turunen, H., \& Snelgrove, S. (2016). Theme development in qualitative content analysis and thematic analysis. Journal of Nursing Education and Practice, 6(5), 100-110. https://doi.org/10.5430/jnep.v6n5p100.

Yan, Z. (2020). Unprecedented pandemic, unprecedented shift, and unprecedented opportunity. Human Behavior and Emerging Technologies, 2(2), 110-112. https://doi.org/10.1002/hbe2.192.

Publisher's note Springer Nature remains neutral with regard to jurisdictional claims in published maps and institutional affiliations.

\title{
Authors and Affiliations
}

\author{
Orit Ezra $^{1} \cdot$ Anat Cohen $^{1}$ (D) Alla Bronshtein ${ }^{2} \cdot$ Hagit Gabbay $^{1} \cdot$ Orit Baruth $^{1}$ \\ Orit Ezra \\ oezra1@gmail.com \\ Alla Bronshtein \\ allab@tauex.tau.ac.il \\ Hagit Gabbay \\ hg.astd@gmail.com \\ Orit Baruth \\ oritbaruth@gmail.com \\ 1 School of Education, Tel Aviv University, Ramat Aviv, P.O.B 39040, 69978 Tel Aviv, Israel \\ 2 Faculty of Medicine, Tel Aviv University, Tel Aviv, Israel
}

